\title{
ÁLVAREZ RIXO Y EL INVENTARIO TOPONÍMICO DE CIPRIANO GORRÍN
}

\author{
Carmen Díaz Alayón \\ Universidad de La Laguna
}

\section{Resumen}

Álvarez Rixo dedica una parte considerable de su tiempo a la creación y a la recogida de materiales, firmemente convencido, como él mismo nos dice, de que "todos los sucesos que no se consignan al papel finalmente se olvidan o alteran en las tradiciones". Su producción asombra por su amplitud y variedad, destacando las aportaciones de carácter histórico, pero también hay lugar para contribuciones de carácter lingüístico, literario, y antropológico, entre otras áreas. En esta ocasión el análisis se focaliza en una pieza inédita de su archivo personal, el Diccionario geográfico de estas Islas Canarias, intentado por el joven D. Cipriano Gorrín, natural del Puerto de la Cruz, en 1816. Se trata de un proyecto que no se concluye, pero que posee la relevante cualidad de ser el primer intento de elaborar un repertorio toponímico que se hace en Canarias.

Palabras clave: Toponimia, documentación, Canarias, Álvarez Rixo, Cipriano Gorrín.

\section{ÁLVAREZ RIXO AND THE TOPONYMIC LIST BY CIPRIANO GORRÍN}

\begin{abstract}
Álvarez Rixo devotes much of his time to create and collect materials, firmly convinced, as he himself confess, that "all events that are not recorded in writing are finally forgotten or altered in traditions". His work is astonishing in extension and variety; the historical research is to be emphasized, but there is also place for contributions of linguistic, literary and anthropological nature, amongst other areas. On this occasion, the analysis is focused on an unpublished piece of his personal archive, the Diccionario geográfico de estas Islas Canarias, intentado por el joven D. Cipriano Gorrín, natural del Puerto de la Cruz, en 1816. This is an unfinished project, but it has the relevant quality of being the first attempt to develop a toponymic catalogue made in the Canaries.

Keywords: Toponymy, documentation, the Canaries, Álvarez Rixo, Cipriano Gorrin.
\end{abstract}


El autor e investigador tinerfeño José Agustín Álvarez Rixo (1796-1883) dedica una parte considerable de su tiempo ala creación y a la recogida de materiales de todo tipo, dando forma a una obra singular que asombra por su amplitud y variedad, y que lo convierten, sin duda alguna, en la memoria canaria del sigloxix ${ }^{1}$. Pero en esta ocasión no me voy a detener en su faceta de hombre dedicado permanentemente a sus aportaciones propias, sino que dirijo mi mirada al Álvarez Rixo documentalista, al hombre que no deja de llamar la atención una y otra vez sobre la necesidad de preservar los fondos bibliográficos y documentales insulares, una buena parte de los cuales acaba irremisiblemente como papel de envolver en tabernas, ventas y especerías, una perversa práctica que denuncia en numerosas ocasiones, como en las líneas iniciales delartículo periodístico "Noticia de algunos acaecimientos enlaislade Canaria...", de abril y mayo de 1841 (apud Díaz Alayón y Castillo, 2005: 184):

Pero nada de esto eran sino apuntaciones sin orden sobre diversos acaecimientos de nuestras islas. Y pareciéndole inútiles, dijo que sus hijos los gastarian en hacer cometas, o algún tabernero le daria 8 cuartos por ellos. Dolime de la destrucción que iban a sufrir aquellos borradores como ha sucedido con no pocos de esta clase que han ido a parar a manos de quienes no saben lo que son, y le di unas fiscas en cambio...

Me interesa, como digo, esa otra parte de su valiosa labor que lo muestra siempre atento a otras contribuciones que llegan a su conocimiento y que conserva para que se puedan transmitir. Gracias a sus desvelos en este sentido, entre otros textos, hoy podemos disponer de los dos opúsculos Usos y costumbres de los aldeanos de esta isla de La Palma y Apellidos y apodos de los palmeros, escritos por Antonio Lemos Smalley (1788-1867) y que este envía a nuestro documentalista para que haga una copia, que afortunadamente es la versión que se ha conservado (Díaz Alayón y Castillo, 2006). Tal es el caso, también, de una recopilación toponímica que forma parte del singular archivo de Álvarez Rixo y que, por su interés, estudio en esta ocasión. Se trata de un manuscrito que no lleva título, pero todo apunta a que sea el que nuestro investigador relaciona bajo el título de "Borrador manuscrito del Diccionario geográfico de estas Islas Canarias, intentado por el joven D. Cipriano Gorrín, natural del Puerto de la Cruz, en $1816 n^{2}$, en el n. ${ }^{\circ}$ 30, del apartado F dentro de sus Catálogos de los diversos manuscritos de mi pertenencia y personal trabajo.

${ }^{1}$ Entre un amplio conjunto de contribuciones, véanse Álvarez Rixo (1955, 1982, 1991, 1992 y 1994), Millares Carlo y Hernández Suárez (1975), Díaz Alayón (1990, 2003, 2004a, 2004b, 2005a, 2005b, 2011, 2014 y 2016), Díaz Alayón y Castillo (2005, 2006, 2007, 2008a, 2008 b y 2009).

${ }^{2}$ JAAR 6/7, Archivo personal José Agustín Álvarez Rixo, Biblioteca Universitaria de La Laguna. 
Es un manuscrito compuesto por veinte páginas numeradas y tres de ellas, la 16,17y 18 están en blanco. La mayor parte de las hojas presenta un buen estado de conservación, no así las dos primeras y las dos últimas páginas, apreciablemente más deterioradas. El texto es una simple relación de voces geográficas que viene sin título, sin elementos introductorios o alguna otra referencia que nos indique de dónde se han extraído esos materiales y cuál es el propósito del proyecto. Consta de 356 entradas, que están parcialmente agrupadas alfabéticamente, pero visiblemente desordenadas, por lo que abundan las anotaciones en las que el autor remite a las páginas o columnas donde continúan las referencias. Los datos se consignan a doble columna y se advierten dos escrituras claramente diferenciadas: una, mayoritaria, de trazo pequeño; y otra, de mayor tamaño, mucho más cuidada y regular, que se ve en las formas Abalo, Águila, Alajeró, Álamos, Ansosa, Aragerode, Aragigual, Arasarode, Areguerode y Ayamorna, la mayor parte de las entradas de la letra B, desde Bañadero a Breña Baja, una buen parte de las de la C, todas las de la D, E y F, algunas de la G y todas las correspondientes a la H, Iy J.

Una lectura pausada enseguida nos pone en aviso de que estas voces geográficas, al igual que los comentarios que las acompañan, proceden de la Historia de José de Viera y Clavijo, en concreto de los capítulos que se dedican a la situación de las distintas islas en elúltimo tercio del siglo xviii (lib. 12, $\S 46 ;$ lib. $15, \S \S 87,88,89$ ). Sorprende que los datos de Gorrín únicamente se refieren a Tenerife, Gran Canaria, La Palma y La Gomeray, salvo el caso singular de la forma lanzaroteña Guanapay, faltan los relativos a las restantes; y otro rasgo destacable es que tampoco están todos los topónimos que recoge Viera para las cuatro islas que Gorrín incluye. Todo ello muestra claramente que estamos ante un proyecto en desarrollo y, sin duda alguna, lo novedoso y meritorio reside en el hecho de que se trata del primer inventario toponimico —o toponímico-administrativo, para ser más exactos-hecho en Canarias.

En cuanto a la naturaleza de la información, hay que señalar que el borrador se confecciona en 1816 , tal y como se refleja en el título, pero los materiales corresponden al último tercio del siglo anterior, y el autor sigue en todo momento a su fuente y no corrige ni pone al día sus datos, que en la fecha de la elaboración del borrador ya quedan desfasados tras la creación de los municipios. Esto hace que Gorrín tome al pie de la letra el confuso apartado que Viera le dedica a Firgas, en el que se le adscriben pagos (como es el caso de El Trapiche, Trasmontaña, La Santidad, Los Portales y Masapeses) que corresponden al término de Arucas. Nuestro autor no cuestiona la calidad de los datos de su fuente ni la somete a ninguna comprobación, por lo que reproduce incluso algunos despistes del Arcediano, como se puede ver en las entradas Garachico y Güímar. En el primer caso se da la fecha de 1705 para el volcán que asola esta población y ciega su 


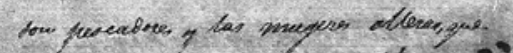

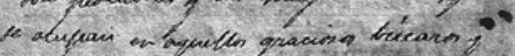

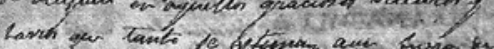
ver vles Caleos de Barachice Ling ifa bungiver ar Gachico

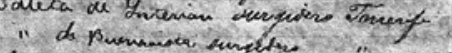
Cueva del Conde durgutero on la clomena el darte Cabrito Plaqa al eterde la

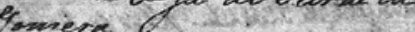
Chingutarime Colaja clolem Chimina corecen

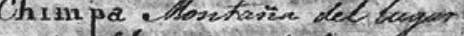
de. Hayero en la eprectra de maty lagradalle quropectin

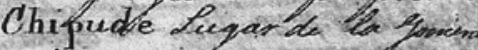
Sace á la falla de un monda espedo, en yu teay secuche cono

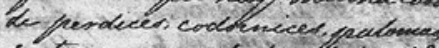

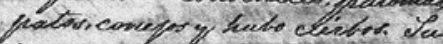
Yolvia Garrogural es dr bina we cose curpe perveciar dil

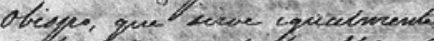
a las feliznear de la tholesde

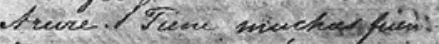

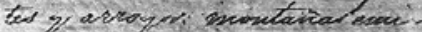

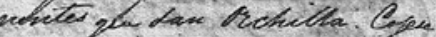

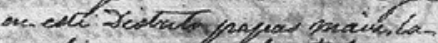

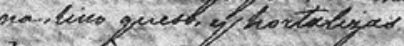

Cabo(el) Pagádel bugende

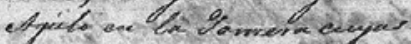

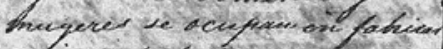

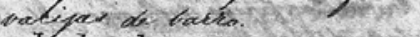

Ciuclad del Real delas Palmas.

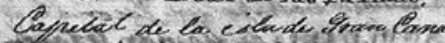

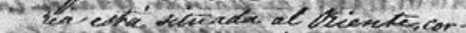

wrestlo for the bi illondil mear

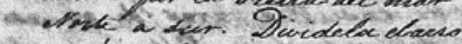

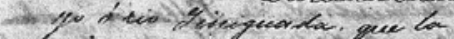

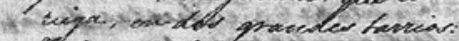

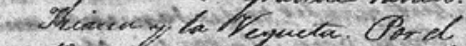
prievite lowle da vievele

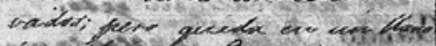

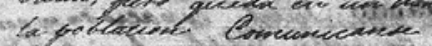

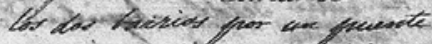
de baditen feargen al inupte del hermender de bex devablece suer fior dos ceres laypeseded pecenter de carderin. A de havied de lo deyenders bece wein

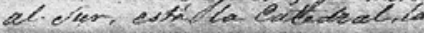

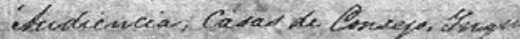

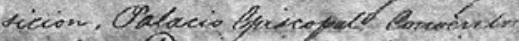

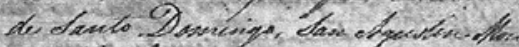

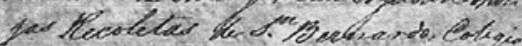
que fur de bos ledvilar deosmilel

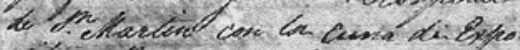

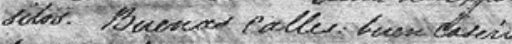
hane flloge con una feerete on th incedios dorede precina al Busienen la factiada te la Catednals, vel biri.

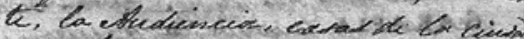
colceled y ceenper da Heandia; ol

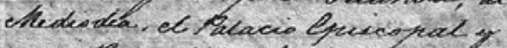

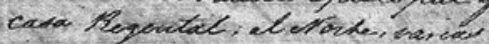
catad the particielowed de counel

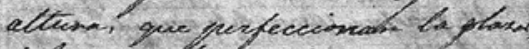
a' la gre delled acabo coller fur Lar élquiners.

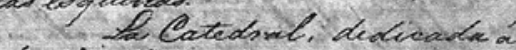

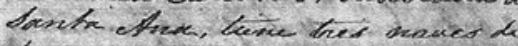
tany y cuatio de evergad fines.

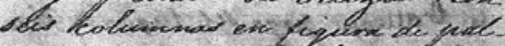

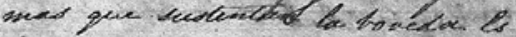

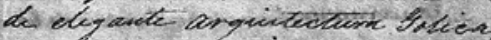

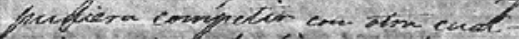

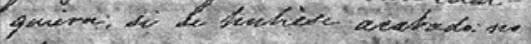

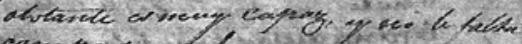

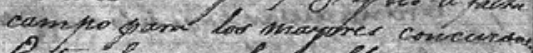

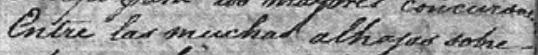

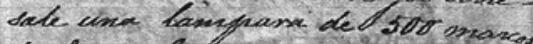

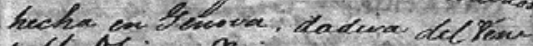

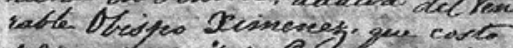

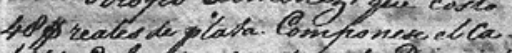

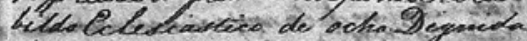
ded dies a revir Camongid llloce.

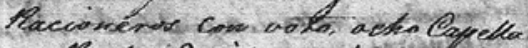

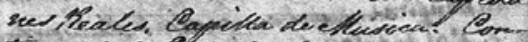
tigua a ba Qbtedrack y a der epr

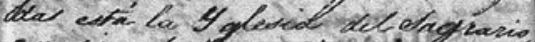

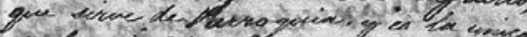

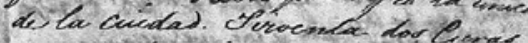

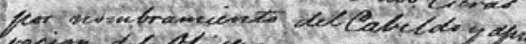
vacen def Oly pro

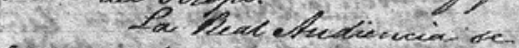

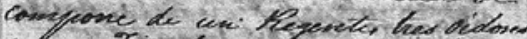

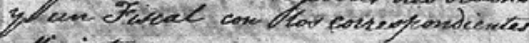

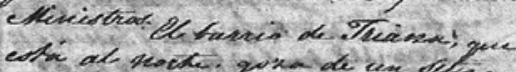

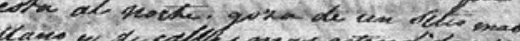

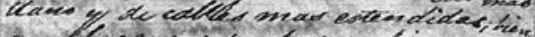

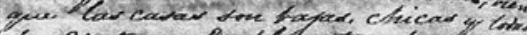

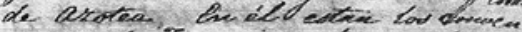
Lad de fre Fowercites tempor de

$$
\text { gada } 20 \text { fold th }
$$


célebre puerto; y en el segundo, la erupción de Güímar se sitúa en el año 1706. Asi viene en Gorrín y en los materiales de Viera que este sigue, pero las fechas están equivocadas. Tenemos que acudir a otros apartados de la Historia para encontrar las fechas correctas (lib. xv, §§ 10, 12).

Hay que señalar, además, que Gorrín también intercala datos propios de carácter histórico, administrativo y económico, que no vienen en la fuente que sigue. Es él el que modifica la entrada Santa Cruz de Santiago, al igual que introduce datos propios al comienzo de la del Puerto de la Orotava, además de las alusiones a la producción de la barrilla en la de Tenerife y a la calidad de las cebollas y plátanos en la de San Juan de la Rambla. Esta circunstancia también se da en la entrada relativa a $L a L u z$.

Por su interés, reproduzco a continuación el borrador de Gorrín. En primer lugar, dada la disposición manifiestamente dispersa de las entradas, se ha procedido a la necesaria reordenación. El principal criterio de edición ha sido respetar plenamente el original, presentando el texto en todas sus peculiaridades. Se reproducen, por tanto, las singularidades del nivel gráfico, en el que se advierte que en algunos casos el autor sigue el sistema que utiliza Viera (acia, perenes), pero en otras ocasiones toma criterios personales (bresos, quinse, pertenese, alcansan, brizas, estremada, provición, mesclan, conosido, hermitas) y utiliza soluciones más modernas. En este sentido se advierte que en los términos que en el Arcediano empiezan por qu-, Gorrín prefiere $c u-y$ también moderniza el uso de $x$ y escribe Adeje, Tirajana, entretejidos y bajan, en lugar de Adexe, Tiraxana, entretexidos y baxan. También prefiere parroquia y parroquial a parrochia y parrochial. De igual forma, se mantiene la acentuación indicativa que se refleja en algunos términos y entre los mínimos cambios introducidos está el desarrollo de las escasas abreviaturas (p.r, q. ${ }^{\mathrm{e}}$, S. ${ }^{\mathrm{n}}, \mathrm{S} .{ }^{\mathrm{ta}}$ ). E1 texto se acompaña de un breve aparato de notas, de especial utilidad para apreciar las características de la aportación de Cipriano Gorrín y la relación de sus materiales con los de Viera y Clavijo.

Diccionario geográfico de estas Islas Canarias, intentado por el joven D. Cipriano Gorrín, natural del Puerto de la Cruz, en 1816

Abalo. Playa en la Gomera, al Norte.

Abiertas, Las. Pago del lugar de Icod de los vinos.

Abrevadero. Pago del lugar de Icod de los vinos.

Acusa. Pago del lugar de Artenára.

Adeje. Villa de señorío en Tenerife pertenecienteálos marqueses de este título [de la casa de Ponte, y hoy á los condes de la Gomera (roto)]. En otro 
tiempo fue Reyno y Corte de Guanches. Dista de Guía dos leguas y catorce de la Laguna. Pásanse nueve barrancos muy profundos en el camino. Adeje está en un terreno de temperamento apacible más cálido que frío, cuya campiña, poblada de mieses ó de cañas dulces y regada de buenas aguas, goza de bellas vistas al mar. Descúbrese mucho horisonte y en él las islas de la Palma, Hierro y Gomera. En la entrada del pueblo está el castillo. El Palacio y Casafuerte es muy grande. Hay un Ingenio de asúcar, elúnico que ha quedado de tantos como hubo en Tenerife. Cógense más de 5000 fanegas de trigo, que con otros frutos y rentas hacen subir el mayorazgo a 12000 pesos. Tiene Iglesia Parroquial. A una legua del lugar está la playa y puerto donde surgen los barcos. Hay cría de camellos.

Afur. Pago del lugar de Taganána.

Agache. Pago dellugar de Güímar.

Agua de García. Pago del lugar de Tacoronte.

Aguas. Pago dellugar de San Juan de la Rambla, en Tenerife.

Aguatar. Pago dellugar de Tijarafe, en la Palma ${ }^{3}$.

Águila. Playa en la Gomera, al Norte.

Agüimez. Villa y Cámara Episcopal, de la cual se intitulan Señores los Obispos de Canaria. Dista 2 leguas de buen camino de Telde. Está en llano á una legua del mar, con bastantes casas arruadas y otras terreras esparcidas. La iglesia Parroquial es pequeña, aseada y servida por un Cura que pone el obispo. Se tiene por el mejor Curato de Canaria. Hay alguna Clerecía y un Convento, tiene 4 hermitas.

Agúlo. Lugar de la Gomera. Es tradición que este lugar se llamó en otro tiempo Angúlo, por ser un valle que solo tiene dos entradas sumamente angostas ${ }^{4}$. Hasta el año de 1739 era de la jurisdicción de Hermigua. Tiene Iglesia Parroquial bien adornada, con cura. Fertilizanle dos arroyos perenes con cuyas aguas trabajan dos molinos y se llena un estanque para regar sus pomares y huertas. Tiene buenas fuentes y espesos montes, produce muchas papas ó patatas, iñames, hortalizas. Tiene bastante caza de aves.

Alajeró. Lugar en la Gomera de 120 vecinos. Está 5 leguas al Sur de la capital. Tiene decente Parroquial con su cura y un alcalde [ordinario. Abunda (roto)] en higuerales, morales, palmas, perales, almendros. Tiene más de 15 fuentes de agua viva.

${ }^{3}$ [Viera trae Aguatar, pero es Aguatabaro, si tenemos en cuentala transmisión documental yoral, Guatabara].

${ }^{4}$ [Como se ve aquí, el autor no advierte que Agulo es una forma prehispánica, al igual que ocurre con Viera, al que sigue]. 
Álamo, El. Pago del lugar de Terori, en Canaria.

Álamos, Los. Pago del lugar de Valle de Hermigua en la Gomera, llamado así por la arboleda de esta especie.

Aldea. [roto]

Aldea. Pago del lugar de Chasna.

Aldea de San Nicolás. En Canaria, dista 3 leguas de Artenára. Mal camino, todo de laderillas angostas de tierra movediza poblada de pinos. Pásase por los llanos de Tirma. La Aldea es un valle llano y vistoso, que se estiende como una legua acia el mar. Pertenese al marqués de Villanueva del Prado.

Almáciga. Pago del lugar de Taganána.

Altabacales. Pago del lugar de Firgas, en Canaria.

Álvarez. Pago del lugar de Tegueste ${ }^{5}$.

Amparo, El. Pago del lugar de Icod de los vinos.

Angostura, La. Pago del lugar de la Vega, en Canaria.

Angostura, La. Pago de la Villa de Agüimez.

Ansosa. Montaña de la Gomera en ellugar de Valle de Hermigua vestida de muchas especies de los mejores árboles, cuya fuente del pajarito preferian los ciervos á todas las aguas del país.

Arafo. Pago del lugar de Güímar.

Aragerode. Montaña en la Gomera.

Aragigual. Montaña en la Gomera.

Arasarode. Pago del lugar de Alajeró, en la Gomera. Tiene muchas aguas por lo cual está poblado de iñames é higueras; y sus vecinos son por la mayor parte ganaderos.

Aray. Pago del Valle de Santiago, en Tenerife.

Araya. Pago del lugar de Candelaria.

Arbejales, Los. Pago del lugar de Terori, en Canaria.

Archenche. Pago del lugar de Arico.

Areguerode. Pago del lugar de Alajeró, en la Gomera. Tiene 3 manantiales copiosos, mucha huerta y una hermita de San Lorenzo muy antigua.

Argual. Pago del lugar de los Llanos, en la Palma. En este lugar y el de Tazacorte están los dos famosos Ingenios de azúcar de las casas de Monteverde, Vandale, Sotomayor, etc.

${ }^{5}$ [El autor separa erróneamente los dos elementos del topónimo Pedro Álvarez, en lugar de tratarlo como una unidad, que es como viene en Viera]. 
Arguayo. Pago del Valle de Santiago, en Tenerife.

Arguineguín. Surgidero al mediodía de Canaria.

Arico. Lugar de Tenerife. Dista de la Granadilla tres leguas y diez de la Laguna. El camino tiene más de treinta barranqueras. Las casas que hay arruadas están donde llaman el "Lomo" mirando al Oriente y aquí queda la Iglesia. El temperamento, cuando no sopla del Este, es benigno. El piso y campiña muy árida, todo de piedra tosca. Del referido "Lomo" á las playas de "Abona" habrá como una legua y alli se halla la hermita de las Mercedes.

Arico nuevo. Pago del lugar de Arico.

Ariñas. Pago del lugar de la Vega, en Canaria.

Aripe. Pago del Valle de Santiago, en Tenerife.

Arona. Pago del lugar de Chasna.

Arrecife. Surgidero [roto].

Arroyos. Pago dellugar de Victoria.

Artazo. Pago de la Villa de Gáldar.

Artenára. Lugar de Canaria. De Tejeda hasta aquí es el camino peligroso por una ladera llena de fugas y grandes precipicios. La planta del lugar es rarísima. En medio de una gran montaña se alcanzan á ver unos agugeros á manera de nidos de aves. Estos vienen á ser un gran número de cuevas en fila, unas cóncavas [como bóvedas (roto)], otras de cielo raso, algu[nas con su (roto)] alcoba para una cama, y [algunas de (roto)] alto y bajo; pero todas en peña, sin más luz que la de la puerta, frescas en verano, abrigadas en invierno, dentro de las cuales no se oyen vientos ni lluvias. Son por la mayor parte obra de los Canarios antiguos. El clima es vario, el agua buena.

Arucas. Lugar de Canaria. Este lugar que se intitula Villa dista 2 leguas largas de la Ciudad. Cielo alegre, temperie admirable, pero pocas casas arruadas. Decente iglesia de tres naves.

Asomada, La. Pago del lugar de Victoria.

Asuage. Pago del lugar de Moya, en Canaria.

Atalaya, La. Pago del lugar de la Vega, en Canaria.

Ayacata. Pago del lugar de Tirajana.

Ayamorna. Aldea de 14 vecinos en la Gomera. Sobresale en sementeras de todo pan.

Azadilla, La. Pago del Realejo de Abajo. 


\section{B}

Bañadero. Pago del lugar de Firgas, en Canaria.

Barlovento. Lugar de la Palma, dista del de Garafia 8 leguas. Para llegar á él se monta la cumbre por un repecho largo, pero sin riesgo aun para las caballerias. Pásase por un bosque de pinos y llaman lo más alto "el risco de los muchachos", de donde corre el Time hasta el mar. Por este paraje se ve también la célebre "Caldera de Taburiente», que provee la isla de pastos y aguas. La bajada es por entre pinos y después por un bosque de bresos y otros diversos árboles. Las casas del lugar son pequeñas, están esparcidas y cubiertas de paja.

Barranco, El. Pago del lugar de Tirajana.

Barranco, El. Una aldea distante una legua de la Villa de San Sebastián en la Gomera. Tiene dos hermitas y es muy amena por razón de sus huertas, bosques y pomares.

Barranco Hondo. Pago de la ciudad de la Laguna, en Tenerife.

Barranco Hondo. Pago de la Villa de Gáldar.

Barranco Hondo. Pago dellugar de Candelaria.

Barrio del Risco. Pago de la Aldea de San Nicolás.

Benchifigua $^{6}$. Pago llamado "corte del señor Conde», á 4 leguas de la Villa de San Sebastián en la Gomera. Se distingue en viñas, palmares, castaños y aguas.

Bentayga. Pago dellugar de Tejeda.

Bodeguilla. Pago dellugar de la Vega, en Canaria.

Breña Baja. Lugar de la isla de la Palma á una legua de la Ciudad, banda del Sur, camino en cuesta y pedregoso. Paraje alegre y cielo despejado, [parroquia pequeña con Cura provisión del Obispo (roto)].

Buen Paso. Pago del lugar de Icod de los vinos.

Buenavista. Lugar de Tenerife, está á media legua de Daute y once de la Laguna. Es terreno llano, pueblo arruado en calles anchas y á cordel, aunque bajas. Hermoso cieloy admirables vistas al mar.

C

Cabedos. Pago dellugar de la Rambla.

Cabezadas, Las. Pago dellugar de Barlovento, en la Palma.

Cabo, El. Pago dellugar de Agúlo, en la Gomera, cuyas mugeres se ocupan en fabricar vacijas de barro.

\footnotetext{
${ }^{6}$ [Viera y Clavijo trae Benchijigua].
} 
Cabo Blanco. Pago del lugar de Chasna.

Caboverde. Pago dellugar de Moya, en Canaria.

Cabrito. Playa al Sur de la Gomera.

Calaboso, El. Pago de la Villa de Guía, en Canaria.

Caldera, La. Pago del lugar de la Vega, en Canaria.

Calderetas. Pago del lugar de los Llanos, en la Palma.

Caleta de Buenavista. Surgidero [en] Tenerife.

Caleta de Garachico. Surgidero en Garachico.

Caleta de Interián. Pago de Daute. Surgidero [en] Tenerife.

Caleta de San Marcos. Ensenada de Icod de los vinos á donde cargan los barcos pequeños los vinos.

Calle, La. Pago del lugar de Victoria.

Canaria. Isla de las de este nombre, esta tiene 12 leguas de largo, 11 de ancho y 48 de circunferencia. Dista 230 leguas de Cádiz. Tierra fértil, sana, de bellas aguas y agradable temperie; célebre por sus dos ó tres cosechas al año, sus deliciosos frutos y sus antiguos Ingenios de azúcar que ya no existen; regalada en carnero, vaca, aves y pesca. Tiene bastante vino, miel, cera, lana, seda, algodón, azeytunas para comer y aun para aceite en un molino de la Villa de Agüimes. No hay fieras ni animales ponzoñosos, zorras, liebres, ni venados. El queso del pago del barranco hondo puede constatarse entre los mejores del mundo. No necesita Canaria de las otras islas, y de ella sale mucho para la de Tenerife y la América. Hay buenas salinas, cuya sal se consume principalmente en la pesca de Berbería. Sus altas cumbres y montañas están vestidas de nieve, árboles y largos pinares. Casi la mitad de la isla hacia Arguineguín está despoblada, tal vez por lo árido del terreno que en lo antiguo abrasaron los volcanes por varias partes. Comprende dos Ciudades y cuatro Villas, quinse Parroquias, tres Hospitales, ochenta y tres Hermitas. Tiene 11 fortificaciones y buenas milicias provinciales, además de la nacional, de la cual hay en la ciudad un Batallón.

Candelaria. Lugar de Tenerife. Dista una legua de Güímar y cuatro de la Laguna. Su situación es en un espacioso arenal, que forma á la orilla del mar mirando al Oriente la ensenada ó boca del barranco. Tiene un suntuoso y bien adornado templo de tres naves, en donde vienen todas las Islas á venerar á su patrona general Nuestra Señora de "Candelaria", hallada entre los Guanches. La Santa Imagen se viste de algunos años á esta parte con riquísimos vestidos y tiene muchas y muy preciosas joyas, un elegante camarín, gran trono de plata, lámparas y otras muchas alhajas, votos de los fieles y peregrinos El convento está [contiguo á un 
alto risco por la espalda. Por lo general todos los vecinos (roto)] son pescadores y las mujeres olleras, que se ocupan en aquellos graciosos búcaros y barros que tanto se estiman aun fuera de las Islas.

Cantera y Lomo. Pagos del lugar de la Granadilla, en Tenerife.

Cañas, Las. Pago del lugar de Icod de los vinos.

Carboneros, Los. Pago del lugar ${ }^{7}$ de la Laguna, en Tenerife.

Caridad, La. Pago del lugar de Tacoronte.

Carrizal. Pago de la Villa de Agüimez.

Carrizal, El. Pago del lugar de Tejeda.

Carrizales, Los. Pago del lugar de Buenavista.

Casas Blancas. Pago del lugar de Tirajana.

Castañeros, Los. Pago del lugar de Icod de los vinos.

Catalanes. Pago del lugar de Barlovento, en la Palma.

Caydero, El. Pago de la Villa de Guía, en Canaria.

Cazadores. Pago de la Ciudad de Telde, en Canaria.

Cendro. Pago de la ciudad de Telde.

Cercados, Los. Pago del lugar de Victoria.

Cerrillo. Barrio del lugar de Firgas, en Canaria.

Chasna. Lugar de Tenerife, por otro nombre Villa-flor. Dista dos leguas de Adeje y trece de la Laguna. Es arruado en una calle larga aunque desigual y pendiente, por ser aquel un vallecito poblado de árboles frutales, pero como es grande la altura lo es también el frío. Allí nieva todos los inviernos [por uno y otro lado (roto)] empiezan las cumbres y los [pinos. Las aguas (roto)] son las más celebradas de las Canarias. Haylas agrias y medicinales. Es país feracísimo en trigo si llueve á tiempo. Tiene buena Iglesia Parroquial. Está aquí el término de Abona, que fue también Corte de Rey Guanche; y es patria del Venerable Pedro de San José Bethencourt, fundador de los bethlemitas en Indias.

Chimisay. Playas en el término de Güímar.

Chimpa. Montaña del lugar de Alajeró, en la Gomera, de muy agradable perspectiva.

Chináma. Pago del lugar de Chasna.

Chinguarime. Playa al Sur de la Gomera.

Chinguaro. Barranco en el término de Güímar.

\footnotetext{
${ }^{7}$ [Asi en el manuscrito original, pero debe ser ciudad].
} 
Chío. Pago del Valle de Santiago, en Tenerife.

Chipude. Lugar de la Gomera. Yace á la falda de un monte espeso, en que hay mucha caza de perdices, codornices, palomas, patos, conejos y hubo cierbos. Su Iglesia Parroquial es de 3 naves con cura provición del Obispo, que sirve igualmente á los feligreses de la Aldea de Arure. Tiene muchas fuentes y arroyos, montañas eminentes que dan Orchilla. Cójese en este Distrito papas, maíz, lana, lino, queso y hortalizas.

Chirche. Pago del Valle de Santiago, en Tenerife.

Chorrillo. Pago de la ciudad de la Laguna.

Chorrillo, El. Pago del lugar de Tejeda.

Chorros, Los. Pago del lugar de la Vega, en Canaria.

Cisnera. Pago del lugar de Arico.

Ciudad del Real de las Palmas. Capital de la isla de Gran Canaria, está situada al Oriente, corriendo por la orilla del mar Norte á Sur. Divídela el arroyo ó río Giniguada, que la riega, en dos grandes barrios: Triana y la Vegueta. Por el Poniente tiene dos riscos elevados; pero queda en un llano la población. Comunícanse los dos barrios por un puente de madera, porque el ímpetu del barranco se ha llevado al mar por dos veces dos fuertes puentes de cantería. En el barrio de la Vegueta, que mira al Sur, está la Catedral, la Audiencia, Casas de Consejo, Inquisición, Palacio Episcopal, Conventos de Santo Domingo, San Agustín, Monjas Recoletas de San Bernardo, Colegio que fue de los Jesuitas, Hospital de San Martín con la Cuna de Expósitos. Buenas calles, buen caserío, buena plaza con una fuente en el medio, donde mira al Poniente la fachada de la Catedral; al Oriente, la Audiencia, casas de la Ciudad, Cárceles y Cuerpo de Guardia; al Mediodía, el Palacio Episcopal y casa Regental; al Norte, varias casas de particulares de igual altura, que perfeccionan la plaza á la que salen cuatro calles por las esquinas.

La Catedral, dedicadaá Santa Ana, tiene tres naves delargoy cuatro de cruzado, con seis columnas en figura de palmas que sustentan la bóveda. Es de elegante arquitectura Gótica y pudiera competir con otra cualquiera si se hubiese acabado; no obstante es muy capaz y no le falta campo para los mayores concursos. Entre las muchas alhajas sobresale una lámpara de 500 marcos hecha en Génova, dádiva del Venerable Obispo Ximénez, que costó 48000 reales de plata. Compónese el Cabildo Eclesiástico de ocho Dignidades, diez y seis Canongias, doce Racioneros con voto, ocho Capellanes Reales, Capilla de Música. Contigua á la Catedral y á sus espaldas está la Iglesia del Sagrario, que sirve de Parroquia, y es la única de la Ciudad. Sírvenla dos Curas por nombramiento del Cabildo y aprovación del Obispo. 
La Real Audiencia se compone de un Regente, tres Oidores, y un Fiscal con los correspondientes Ministros.

El barrio de Triana, que está al Norte, goza de un sitio más llano y de calles más estendidas; bien que las casas son bajas, chicas y todas de azotea. En él están los Conventos de San Francisco, Monjas de San Bernardo y de Santa Clara, con el Hospital de San Lázaro. Este último, dentro de muros pero separado de la Ciudad, sirve para los enfermos Elefancíacos ó Dañados que abundan en las Islas. E $1^{8}$ Hospital Real con sagrario. Gobiérnalo el Oidor Decano como Juez conservador y un Capellán que llaman Manpastor los Lazarinos. Dentro de murallas tiene la Ciudad 11 hermitas.

En los referidos riscos, que dominan toda la Ciudad, hay gran número de cuevas y casucos ${ }^{9}$ de tierra, habitadas por gente pobre. Sobre el cerro de San Nicolás, que hace abrigo a Triana, está el castillo que llaman del Rey, de una de cuyas plataformas corre la muralla hacia $\mathrm{al}^{10}$ Norte. Al pie yace el Castillo de Casa-Mata; y luego sigue por lo llano al de Santa Ana en el mar, cerca del cual está la puerta de la Ciudad con una estacada ó rastrillo. Por esta se va al Puerto de la Luz. Fórmanle las cuatro montañas elevadas de las Isletas, quedando defendido de todos vientos, menos del Sud-Oeste. Resguárdanlo los Castillos de la Luz y Santa Catalina. Hacia el Norte, mirando á Tenerife, forma otros dos puertecillos la Isleta: el Confital, en donde se recojen las piedrecillas de la más perfecta figura de Confites; y el Arrecife, en donde se levantó un reducto. La puerta de los Reyes, por donde se sale para Telde, está al mediodía de la Ciudad y por aquella costa hay otras dos fortificaciones.

El Temperamento es benigno y tan igual que casi no se nota diferencia del invierno al verano; bien que la Primavera suele ser triste por los vientos que llaman brizas pardas y encapotan la tierra. Esta es muy amena en huertas y jardines, por el abundante riego de que goza. Excelentes frutas, carnes, pescados, aves, etc. Buenos paseos y salidas. Ciudadanos sociables y corteses.

Colmenar. Pago de la Ciudad de Telde, en Canaria.

Colmenar. Pago del lugar de San Lorenzo, en Canaria.

Colmenillas. Pago de la Villa de Guía, en Canaria.

Confital. Surgidero al Norte de Canaria.

Cordillera. Pago de la ciudad de la Laguna, en Tenerife.

Cornadillos. Pago de la Villa de Agüimez.

\footnotetext{
${ }^{8}$ [Así en el manuscrito original, pero debe ser $\left.E s\right]$.

${ }^{9}$ [Así en el original. Viera trae casucas].

10 [Así en el original].
} 
Corte de la Nao. Pago del lugar de Icod de los vinos.

Corugera. Pago del lugar de Santa Úrsula.

Costa, La. Pago del lugar de Moya, en Canaria.

Costa de Layraga. Pago de la Villa de Guía.

Costas. Pago del lugar de Tejeda.

Cruces, Las. Pago del lugar de Daute.

Cruz Santa. Pago del Realejo de arriba.

Cueva Bermeja. Pago de la Aldea de San Nicolás, en Canaria.

Cueva del Conde. Surgidero en la Gomera, al Norte.

Cuevas, Las. Pago del lugar de la Vega, en Canaria.

Cuevas Blancas. Pago de la Ciudad de la Laguna.

Cumbre, La. Pago de la Villa de Agüimez.

Daute. Pago del lugar de los Silos.

Degollada, La. Pago del lugar de Arico.

Desaguaderos, Los. Pago de la Villa de Guía.

Dragonal. Pago del lugar de San Lorenzo, en Canaria.

Dragos, Los. Pago del lugar de Moya, en Canaria.

Draguillo. Pago de la Ciudad de Telde.

Draguito. Pago del lugar de la Granadilla.

$\mathrm{E}$

Erjos. Pago del lugar de los Silos.

Escalona. Pago del lugar de Chasna.

Esparragal. Pago del lugar de los Silos.

Esperanza, La. Pago de la Ciudad de la Laguna, en Tenerife.

Evercón. Pago de la Aldea de San Nicolás.

Falayraga. Pago de la Villa de Guía.

Fasnia. Pago del lugar de Arico.

Fatága. Pago del lugar de Tirajana.

Firgas. Lugar de Canaria que tiene Canteras de piedra para fábricas y enlosados. 
Foco de Mián. Pago de la Aldea de San Nicolás.

Fonche. Pago dellugar de Chasna.

Fondillo. Pago del lugar de Tejeda.

Fontanal. Pago dellugar de Moya, en Canaria.

Fuente, La. Pago del lugar de Buenavista.

Fuentecillas. Pago del lugar de Firgas, en Canaria.

Fuente de la Guancha, La. Lugar de Tenerife. Queda á media legua de San Juan de la Rambla, hacia la cumbre. Es frío y destemplado. Las casas están esparcidas por las heredades. Abunda en papas ó patatas.

Fuente de la Vega y cerro gordo. Pago del lugar de Icod de los vinos.

G

Gáldar. Villa de Canaria. El camino desde Lagaete es como de una legua llana. Fue Corte de los Guanartemes y hoy se intitula Villa. Está situada en una vega de cielo saludable y de alegre temperie. Tiene número de casas arruadas y algunas cuevas de los Canarios antiguos. El Palacio de los Guanartemes sería en su tiempo un Escorial; y no dejan de llamar todavía la atención aquellas paredes de casi tres varas de grueso de piedras de Sillería también [sic] ajustadas y cubiertas de tablones grandes perfectamente unidos y acepillados sin clavos, sin barro, cal, ni yeso.

Gallego, El. Pago de la Villa de Guía.

Gallegos, Los. Pago del lugar de Barlovento, en la Palma.

Gambuesa, La. Pago del lugar de Arico.

Gamonal, El. Pago del lugar de la Vega, en Canaria.

Gando. Surgidero al Oriente de Canaria.

Gando. Puerto espacioso y cómodo entre Telde y Agüimez, en Canaria.

Garachico. Lugar de Tenerife. Está á una legua de Icod y diez de la Laguna. Bájase á él por la cuesta del "Guincho" sobre la rivera del mar. Fue uno de los mejores, más ricos, más amenos y más florecientes pueblos de las Canarias, pero después que en 1705 lo devastó un volcán, cegándole el puerto, abrasando sus campos y sus casas, y ahuyentando el comercio, la alegria y las gentes, no es Garachico más que un desengaño como Troya. Está á lo largo de la orilla del mar, de este a Oeste, con tres calles principales y las que atraviesan. Enfrente, esto es al Norte, hay un roque en el mar que forma como un río con la costa. Es buen temperamento cógense regalados pescados.

Garafía. Lugar al Oeste de la Palma. El camino á este lugar, desde PuntaGorda, empieza en una larga barranquera. Sigue un monte de pinos 
y matorrales y luego otros barrancos y malos pasos. En suma, "la más quebrada y áspera tierra del mundo", como dice el Sr. Obispo Murga, por los innumerables repechos, bajadas, fugas y cuatro barrancos que no se les ve fin. Su temperie estremada en calor y frío, además de ser fuertes y continuos los vientos.

Gavilán. Pago del lugar de Arico.

Gazaga. Pago de la Villa de Gáldar.

Geneto. Pago de la Ciudad de la Laguna.

Goleta, La. Pago del lugar de Tegueste.

Goteras. Pago de la Ciudad de la Laguna.

Goteras, Las. Pago de la Ciudad de Telde.

Goteras, Las. Pago del lugar de la Vega, en Canaria.

Granadilla. Lugar de Tenerife. Dista de Chasna dos leguas de buen camino y trece de la Laguna. Está el lugar situado en un vallecito, mirando al mediodia; piso desigual, pero temperamento apacible. Es tierra fértil en trigo, tanto que ha solido dar ciento por uno. Hay crías de ganado y de seda. Tiene Iglesia.

Granadillar. Pago de la Ciudad de la Laguna.

Granero. Pago del lugar del Tanque.

Guadaya. Pago del lugar de Tejeda.

Guamaza. Pago de la Ciudad de la Laguna, en Tenerife.

Guanapay. Castillo en Lanzarote.

Guancha. Playa al Sur de la Gomera.

Guayadeque. Pago de la Villa de Agüimez.

Guayedra. Pago de la Aldea de San Nicolás.

Gueste. Pago del lugar de Candelaria.

Guía. Villa de Canaria. Está comoá media legua de Gáldar en sitio alegre, sano, llano y de buenas aguas, sin duda es el pueblo mejor y de más lustre después de la Capital. Su Iglesia es de 3 naves, bien adornada y servida de un Beneficiado provición de S.M. Hay un Hospicio de San Francisco en donde se enseñan Gramática y primeras letras. Tiene cinco hermitas.

Guía. Pago del lugar de la Victoria.

Guía. Lugar de Tenerife. Dista del Valle de Santiago como 3 leguas de malpaís y laderay 13 de la Ciudad de la Laguna. Es ayuda de Parroquia del referido Valle. La iglesia pequeña, dedicada a Nuestra Señora de Guía, da nombre moderno al territorio que antes era conosido por Ysora. Todo el terreno es un volcán antiguo al pie de la cumbre con buenas aguas y ayres frescos. 
Güímar. Lugar de Tenerife. Está cinco leguas de Arico y otras cinco de la Laguna. Es un valle alegre, de algunas viñas, tierras de pan sembrar y numerosos higuerales, cuyo fruto después de pasado es el mejor. El temperamento cálido, el agua buena, los moradores pobres, las casas dispersas. El volcán de 1706 quemó mucha parte del territorio, que en lo antiguo daba cañas de asúcar y tenía Ingenio. Dista una legua del mar. La iglesia parroquial es decente. Fue cabeza de Reyno en tiempo de los Guanches y en su término se halla el famoso barranco "Chinguaro" $y$ las playas de "Chimisay".

$\mathrm{H}$

Helechal. Pago de la Ciudad de Telde.

Herquito. Pago del lugar de Chipude. Es muy ameno y rinde miel de palmas y sedas.

Higa. Pago de la Villa de la Orotava.

Higuera. Pago del lugar de la Vega, en Canaria.

Higuera, La. Pago del lugar de la Granadilla.

Hoya. Pago del lugar del Realejo de abajo.

Hoya de Niebla. Pago de la Ciudad de Telde, en Canaria.

Hoya de Pineda, La. Pago de la Villa de Guía.

Hoyas, Las. Pago del lugar de Buenavista.

Hoyo, El. Pago de la Aldea de San Nicolás.

Huerta de Sardina. Pago de la Ciudad de Telde, en Canaria.

Humilladero. Pago de la Ciudad de la Laguna.

Imada. Valle y pago del lugar de Alajeró, en la Gomera. Tiene 12 vecinos, es un paraíso abreviado por la espesura y variedad de árboles frutales, nogales, viñas, morales, higuerales y perales.

Juncal. Surgidero al Norte de Canaria.

$\mathrm{L}$

Lagaete. Surgidero al Poniente de Canaria.

Lagunetas. Pago del lugar de La Vega, en Canaria.

Lauretal. Pago del lugar de San Lorenzo, en Canaria. 
Lechuza, La. Pago del lugar de La Vega, en Canaria.

Llano, El. Pago dellugar de Santa Úrsula.

Llanos, Los. Pago del lugar de la Granadilla.

Llanos, Los. Lugar de la Palma á 4 leguas de Mazo, camino en cuesta pues se monta á la cumbre, pero sin peligro y poblado de bosques. Las más de las casas son terreras y en buen número arruadas. Terreno llano, temperamento cálido, cielo sereno, aguas salutíferas. Abunda en frutos, por lo que están allí los mejores mayorazgos de la Isla.

Llanos de Jós. Pago del lugar del Tanque.

Lomada de Briestra. Pago del lugar de Garafia, en la Palma.

Lomada de Cueva de Agua. Pago del lugar de Garafia, en la Palma.

Lomada de Don Pedro. Pago del lugar de Garafia, en la Palma.

Lomada de Fagundo, La. Pago del lugar de Punta Gorda, en la Palma.

Lomada de Fernando Oporto. Pago del lugar de Garafia, en la Palma.

Lomada de Franceses. Pago del lugar de Garafia, en la Palma.

Lomada de Juana de Adali. Pago del lugar de Garafia, en la Palma.

Lomada de Salvatierra. Pago del lugar de Garafia, en la Palma.

Lomada de San Amaro, La. Pago del lugar de Punta Gorda, en la Palma.

Lomada de Santo Domingo. Pago del lugar de Garafia, en la Palma.

Lomada de las Tricias. Pago del lugar de Garafia, en la Palma.

Lomada del Mudo. Pago del lugar de Garafia, en la Palma.

Lomada del Palmar. Pago del lugar de Garafia, en la Palma.

Lomada del Pinal, La. Pago del lugar de Punta Gorda, en la Palma.

Lomada del Roque, La. Pago del lugar de Punta Gorda, en la Palma.

Lomada del Tablado. Pago del lugar de Garafia, en la Palma.

Lomada Grande. Pago del lugar de Garafía, en la Palma.

Lomo Espino. Pago del lugar de la Vega, en Canaria.

Lugarejo. Pago del lugar de la Vega, en Canaria.

Luz, La. Pago de la Villa de la Orotava en el centro del Valle. Tiene una ermita y cosa de 150 á 200 almas $^{11}$.

$\mathrm{M}$

Malpaís. Pago del lugar de Victoria.

Manchas, Las. Pago del lugar de los Llanos, en la Palma.

\footnotetext{
${ }^{11}$ [Esta información no viene en Viera].
} 
Manchas, Las. Pago del Valle de Santiago, en Tenerife.

Masapeses. Pago del lugar de Firgas, en Canaria.

Masca. Pago del Valle de Santiago, en Tenerife.

Maspalomas. Surgidero al mediodía de Canaria.

Matanza. Lugar de Tenerife al este. Dista media legua del Sauzal y dos y media de la Laguna. Llamose en otro tiempo Acentejo; y Matanza después de la derrota de los españoles en aquel sitio por los Guanches. Es terreno de buenas viñas, pueblo poco arruado.

Mazo. Lugar de la Palma. Dista dos leguas de la Breña, cuyo camino es bueno y divertido por los árboles. Son de madera la mayor parte de las casillas y muchas cubiertas de paja; pero todas esparcidas por los barrancos y laderas. El temperamento es frío, el cielo melancólico, el agua se conserva en aljives de madera calafateados. Hay viñas y frutas. Aquí estaba la "Fuente Santa" o "Foncaliente», nombre del cabo meridional de la Isla.

Medianías. Pago del lugar de Barlovento, en la Palma.

Miradero, El. Pago del lugar de Icod de los vinos.

Mocán, El. Pago del Realejo de arriba.

Montañas. Pago de la Ciudad de la Laguna.

Moral, El. Pago del lugar del Sauzal, en Tenerife.

Pago de Pedro. Pago del lugar de Tegueste ${ }^{12}$.

Palma. Isla delas Canarias, la más occidente después del Hierro. Conquistada por Alonso Fernández de Lugo. Es de 10 leguas de largo, 9 de ancho y 27 de circunferencia ${ }^{13}$. Todos sus Pueblos están sobre las costas. Es abundante en vinos, azúcar, almendras, miel, cera y seda que se fabrica. Fértil en todo género de frutas esquisitas, de que se hacen confituras. Escasa de granos. Mantiénense los pobres de la raíz del elecho, que reducida á polvo mesclan con harina de centeno de que hacen pan. Tiene altas cumbres, caminos fragosísimos, profundos barrancos, cuevas estupendas. Está vestida de espesos bosques y grandes pinares, de cuyas maderas se construyen barcos y navíos. Encuéntrase allí la célebre "Leña Noel" ó "Ligno Aloes". Las aguas son buenas y abundantes, excepto á la banda del Sur. Nieva en sus cumbres y dura la nieve todo el año en sus barrancos sin empozarla. Padeció muchos volcanes en todos tiempos. No tiene animales ponzoñosos, ni ranas, ni gorriones ni fieras. Goza de suficientes

\footnotetext{
${ }^{12}$ [Como ya se ha adelantado, debe ser Pedro Álvarez].

${ }^{13}$ [Estos datos iniciales no vienen en Viera].
} 
carnes. No hay perdices, liebres, olivos, abellanas, arroz, ni aun hortalizas. Generalmente es país sano, bien que á cada paso se nota variedad de temples. Resguárdanla diez fortificaciones. Mantiene dos atalayas, una en el risco de la Concepción y otra en la Montaña de Tenágua.

Palmas, Las. Pago del lugar de Taganána.

Palmita, La. Pago del lugar de Barlovento, en la Palma.

Palomas. Pago dellugar de la Granadilla.

Paso, El. Pago del lugar de los Llanos, en la Palma.

Paso de María de los Santos. Pago de la Villa de Guía, en Canaria.

Pedregal. Pago del lugar de Icod de los vinos.

Pedregales. Pago dellugar de Barlovento, en la Palma.

Pinal. Pago dellugar de la Granadilla.

Pinal de Ojeda y Lauretal. Pago del lugar de Terori, en Canaria.

Pino Santo. Pago del lugar de la Vega, en Canaria.

Portales, Los. Pago del lugar de Firgas, en Canaria.

Portalina. Pago dellugar de San Juan de la Rambla.

Portezuelo. Pago del lugar de Tegueste.

Puerto de la Luz. Surgidero al oriente de Canaria.

Puerto de la Madera. Pago del lugar de Tacoronte.

Puerto de la Orotava ó de la Cruz. Elde más consideración después de Santa Cruz en Tenerife. Situado al Norte de la Isla es Pueblo con mucho comercio con el estranjero, en el cual sobresaleá Santa Cruz ${ }^{14}$. Dista medialegua de la Villa, está á la orilla del mar en una punta llana y baja que hace la tierra casi en medio del Valle, á cuyos costados quedan dos ensenadas que forman las bocas de los barrancos de Martiánez y Puerto-Viejo. Solo tiene de Puerto el nombre. En la realidad es un buen surgidero para las naves mercantes que cuando se levanta temporal tienen que hacerse á la vela y correr en mar ancha. La población es hermosísima, un temple sano, alegre, sin calor que ofenda, ni frío que incomode. Buenas calles y anchas, buen caserio, buenas plazuelas, buenos paseos por la marina, buena agua, buenas huertas en el sitio de "Martiánez", excelente jardín en el de la "Paz", una gran fuente en la plaza de la Parroquia.

Punta de Anaga. Pago del lugar de Taganána, en Tenerife, y surgidero.

Punta de Buenavista. Cabo al oeste de Tenerife que con el de Teno forman una espaciosa ensenada.

\footnotetext{
${ }^{14}$ [Estas líneas iniciales no vienen en Viera. Pertenecen a Gorrín].
} 
Punta de Teno. El cabo mayor de Tenerife situado al oeste de la Isla.

Punta del Hidalgo. Cabo al Norte de Tenerife.

Punta Gorda. Lugar de la Palma. Dista de Tijarafe camino de tres horas peligroso á causa de dos barrancos muy profundos y de ser todo tierra quebrada. Las casas todas son bajas, cubiertas de paja y muy dispersas.

Punta Llana. Lugar al este de la Palma. El camino á este lugar no cede en aspereza á otro ninguno de la Isla. Antes de llegar á la hermita de San Bartolomé hay dos barrancos. Es terreno abundante en aguas y frutas. Tiene una fuente muy celebrada. Agradables vistas, mugeres hermosas, temperie sana.

Rambla. Pago del Realejo de abajo.

Realejo de abajo. [Lugar de Tenerife. Dista una legua de la Orotava y seis de la Laguna. Tiene buenas casas arruadas en calles muy pendientes. Temperie sana, cielo puro, aguas abundantes y buenas, grandes viñas, haciendas, sitios y pagos deliciosos. Acia poniente el alto cerro de Tygayga con ermita al pie y en la eminencia la llanura alegre de Icod el alto. Al mediodía la famosa hacienda del Adelantado, llamada de los Príncipes. Al Oriente la de la Gorvorana del marquesado de la Breña, y el jardín de (roto)] "Zamora". Al Norte, la "Rambla", el "Burgao", etc., todos terrenos amenísimos.

Realejo de arriba. Lugar de Tenerife. Dista un corto paseo del otro, es de buen temple, excelentes aguas, huertas, viñas, frutales y arboledas. Tiene muchas casas arruadas en calles. Tomó su nombre de haber sido el sitio donde los Conquistadores tenían su Real.

Retamal. Pago del Valle de Santiago, en Tenerife.

Rincones, Los. Pago del lugar de Buenavista.

Río. Pago del lugar de Arico, en Tenerife.

Rosa, La. Pago del Valle de Santiago, en Tenerife.

Rosa vieja. Pago del lugar del Tanque.

Rosas. Pago del Realejo de arriba.

Sabina alta. Pago del lugar de Arico.

Salto. Pago del lugar de la Granadilla.

San Agustín. Pago del Realejo de arriba.

San Andrés. Pago del lugar de Firgas, en Canaria. 
San Antón. Pago de la ciudad de la Laguna.

San Bartolomé. Pago de la Ciudad de la Laguna.

San Cristóbal de la Laguna. Ciudad de Tenerife plantada en una perfecta llanura, larga, ancha; las calles casi á cordel, bien cortadas, bien empedradas y espaciosas, pero tristes; grandes plazuelas, torres, buenos edificios, ayres frescos, aguas excelentes, salidas deliciosas, mantenimiento sólido; todo esto junto contribuye á hacerla un pueblo recomendable. Solo que es húmeda por razón de las muchas lluvias y de la Laguna que se forma por el invierno en la vega inmediata; pero aunque esta humedad enegrece las paredes por la parte del Norte, es ella causa de que se vean los tejados de las casas antiguas cubiertas de unos singulares bosquecillos del "Sedum majus" o "siempreviva", como dicen en España, y en Canarias "verode" ó yerba puntera, que en la Primavera florece. Dista la Laguna una legua y cuarto de Santa Cruz, camino de coches en cuesta sobre peña con algunos puentes sobre el barranco que desagua en la marina. A la entrada está la Alameda llamada de la Cruz de piedra. Divídese la ciudad en dos villas con dos insignes Iglesias Parroquiales. Es abundante en frutas y hortalizas. Tiene dos fuentes en dos plazas; gran número de molinos de viento en sus inmediaciones; un arroyo por el oriente que lleva agua mucha parte del año con que muelen otros molinos.

San Felipe. Pago del lugar de Icod de los vinos.

San Juan. Pago del lugar de Tacoronte.

San Juan. Pago dellugar de la Granadilla.

San Juan de la Rambla. Lugar de Tenerife dista una legua de los Realejos y siete de la Ciudad de la Laguna. Está en un sitio muy alegre no lejos del mar, vestido de viñas de malvasías. Aquí se cojen las mejores cebollas y plátanos de la Isla por abundar mucho el agua.

San Marcos. Surgidero en Icod de los vinos.

San Miguel. Pago del lugar de Chasna.

San Miguel. Pago de la Ciudad de la Laguna.

San Pedro de Buenavista. Lugar al este de la Palma. Está á una legua de la Ciudad, y es de los mejores lugares de la Palma, adonde pasan el verano muchas familias que tienen allí sus haciendas. Cielo despejado, campaña divertida, viñas y árboles frutales; pero agua solamente la que se recoje de las lluvias en aljives y estanques de madera. Desde la hermita de la Concepción, sobre el lomo, se descubre de un golpe á la derecha los "Llanos", las dos "Breñas" alta y baja; por la espalda "Veloco", "Miraflor" y otros montes y campo; por la izquierda Puntallana, San Andrés, los Sauces, todo el plan de la Ciudad: calles, muralla, fortalezas, bahía; por el frente, las islas de la Gomera y Tenerife. 
San Pedro de Daute. Lugar de Tenerife. Está á un cuarto de legua al pie de la cuesta de Garachico. Es de bello temple, de buenas aguas y viñas, pero corto.

Santa Catalina. Pago del lugar de San Juan de la Rambla.

Santa Cruz. Ciudad capital de la Palma y puerto, está situada á lo largo de la costa del mar, mirando al Oriente, cuya espaciosa bahía es de buen fondo. Tiene una larga y hermosa calle, que corta la Ciudad de un estremo al otro, con nobles edificios, y otra trasera, que solo llega á la mitad; ambas rectas y anchas; pero lo restante del pueblo está en ladera, como en anfiteatro, con callejuelas muy pendientes y de molesto piso. Hay un Hospital con Sagrario para pobres enfermos, y siete Hermitas muy decentes dentro y fuera de la Ciudad. Estuvo en otro tiempo muy florido el Comercio de esta Ciudad. Está defendida de tres castillos y algunas baterías.

Santa Cruz de Santiago. Villa y Puerto capital de las Canarias, demora á la parte del este de la isla de Tenerife. Compite con los mejores Pueblos de las Canarias. Débelo al comercio, débelo á la residencia de las principales autoridades y Jefes, asi nacionales como estrangeros, á escepción de la Audiencia que reside en Canaria y el Cónsul inglés que reside en el Puerto de la Orotava. Es plaza de Armas famosa por sus victorias contra los ingleses. El temperamento, aunque cálido es sano y apacible. Hermoséanlo muchos edificios y bellas casas. Las calles rectas, el piso llano, el cielo puro. En la plaza á que hace frente el castillo de San Cristóbal, hay un gran triunfo de mármol de Carrara, que representa la aparición de la Virgen de Candelaria á los Guanches; otra escelente Cruz de la misma piedra y á la entrada del castillo de San Cristóbal una buena fuente para el abasto del público, que estaba antes en el centro de la plaza. Esta agua viene de más de dos leguas por canales. Es Santa Cruz el emporio de aquel comercio á Europa y á América; por consiguiente hay muchos estrangeros entre sus habitantes. El puerto es de fondo limpio, defendido de todos los vientos menos del Sur. Tiene buen muelle cuyo frente está demolido por el mar. Todo ellugar está bastante fortalecido con mucha artillería, castillos, baterias, redutos y murallas que abrazan toda la marina. Separa el barrio del "Cabo" el barranco de "Tahodio" "5, que lleva agua mucho tiempo del año. Tiene una casa de caridad.

Santa Úrsula. Lugar de Tenerife á media legua de la Victoria y cuatro de la Laguna, poco arruado; territorio sano, alegre, despejado, muchas heredades de viña, agua excelente llamada de "Chimaque", árboles frutales de toda especie.

${ }^{15}$ [Así también en Viera, pero obviamente se trata del barranco de Santos, como figura en las ediciones más recientes]. 
Santidad, La. Pago del lugar de Firgas, en Canaria.

Santo Domingo. Pago dellugar de Victoria.

Sauces. Lugar al Nordeste de la Palma. Dista del antecedente [Santa Cruz de la Palma] 2 leguas de camino agrio. Cerca del pueblo hay un barranco profundo que llaman de la Errada ${ }^{16}$. Es lugar alegre, de buen temperamento, abundante en aguas y frutas, plátanos, dátiles, limones. Hay Ingenio de azúcar.

Sauzal. Lugar de Tenerife está á media legua de Tacoronte. Es pueblo en parte arruado; muchas viñas y agua, excelente temperie y unas bellas vistas al mar, con un surgidero para embarcar á la parte baja de la costa.

Silos. Lugar de Tenerife. Dista una buena legua de Garachico y once de la Laguna. Es agradable su situación, su cieloy todo su campo, en especialla hacienda del pago de "Daute", en donde hay un trapiche de moler cañas dulces; hermosas viñas y frutales, aguas y árboles esquisitos, sembrados y salinas en la costa del mar. Tiene buenas casas arruadas.

Sobradillo. Pago del lugar [sic] de la Laguna.

Socas. Pago del lugar de Icod de los vinos.

Sombrera. Pago del lugar de Arico.

Tablero. Pago de la Ciudad de la Laguna.

Taborno. Pago dellugar de Taganána.

Tacande. Pago del lugar de los Llanos, en la Palma.

Taco. Pago del lugar de Buenavista.

Tacoronte. Lugar de Tenerife, dista una legua de la Laguna, toda de buen camino. Es gran lugar de labradores ricos, tierra fértil de granos, vinos y fruta. Aquí se cogen con abundancia las mejores coles (roto) de la provincia (roto).

Taganána. Lugar al Norte de Tenerife. Dista de la Laguna 4 leguas, pásase el camino por la fuente del Rey y por un frondoso bosque en la ladera tan alta que para bajar al lugar se dan más de 60 vueltas. Está situado en lomo entre dos barrancos.

Tamadaya. Pago del lugar de Arico.

Tamarazayte. Pago dellugar de San Lorenzo.

Tamáymo. Pago del Valle de Santiago, en Tenerife.

\footnotetext{
${ }^{16}$ [Así en el original y también en Viera, pero debe ser Herradura].
} 
Tanque. Lugar de Tenerife padeció mucho daño por el volcán de 1705. Es una tierra infeliz de mal país y ladera. Está sobre Garachico.

[Tanque]. Pago del lugar de Victoria.

Taucho. Pago de la Villa de Adeje.

Taya. Pago de la Villa de Gáldar.

Taydía. Pago del lugar de Tirajana.

Tazacorte. Pago del lugar de los Llanos, en la Palma. En este pago y en el de Argual están los dos famosos Ingenios de azúcar de las casas de Monteverde, Vandale, Sotomayor, etc., á quienes pertenece todo aquel territorio y sus aguas con jurisdicción cerrada. Es puerto de mar, cuya rada la forma la boca del barranco de las Angustias acia el Sud-oeste, que llaman río porque corre todo el año.

Tazarte. Pago de la Aldea de San Nicolás.

Tazartico. Pago de la Aldea de San Nicolás.

Tegina. Pago de Tenerife. Está á un cuarto de legua de Tegueste el viejo. Hay viñas, huertas y sembrados, produce muchas cebollas, de las cuales se cargan barcos para la América ${ }^{17}$.

Tegina. Pago del Valle de Santiago, en Tenerife.

Tegueste. Lugar de Tenerife, está como á una legua de la Ciudad, hacia el Nordeste. Pocas casas arruadas.

Tegueste el nuevo. Pago del lugar de Tegueste.

Tejeda. Entre Tirajana y este lugar queda el barranco de Ayacata, que es muy profundo, en donde se halla una casita rodeada de inmensas montañas. Desde aquí se va siempre subiendo y trepando por la eminencia; luego se baja por el empinado Roque de Nublo, bajada á la verdad de innumerables vueltas, por un piso tan resbaladizo que se escurre la tierra de los pies. Desde lo más alto apenas se ven unas quantas chozas del pueblo.

Tenerife. Es la más rica, la más fértil y de más Comercio de las Canarias. Su fruto principal es el vino malvasía y vidueño. Cógese mucho trigo, cebada, maíz y otros granos y legumbres, aunque no suficiente para el abasto de ella. En una misma tierra se dan dos cosechas de papas. Hay muchas y regaladísimas frutas, plátanos, cañas dulces, ñames, naranjas, limones, castañas [almendras (roto)] dátiles, etc. Cógese mucha seda [para cuyo (roto)] beneficio hay [telares (roto)]. También se coge algún lino, pero no cáñamo. Las carnes son buenas. No hay animales, sabandijas ponzoñosas,

\footnotetext{
${ }^{17}$ [Esta última referencia sobre la producción de cebolla no viene en Viera].
} 
fieras ni gorriones. El pescado de toda la parte del Norte es muy regalado y abundante. Las cumbres muy altas y nevadas en el invierno. Los montes poblados de pinos, laureles, cedros, cipreses, dragos, hayas, etc. El famoso pico preside sobre todo. Es abundante en aguas, fuentes y manantiales, que de lo alto de la sierra por sus veneros bajan al mar; menos por la parte del Sur que escasean. Su caza son perdices, conejos, codornises, palomas y patos. El temperamento bueno, el país saludable. Distínguense entre las aves de canto el "Canario" y el "Capirote", especie de Ruiseñor. Tenerife ha sido devastada de volcanes. Cría ganado, miel y cera, orchilla y barrilla, etc. Sus poblaciones y pagos son más de 192, cabezas de partido cinco. Ha dado á la República y á la Iglesia varones de esfuerzo y de virtud. Hay una Ciudad y tres Villas. Tiene (roto) distribuidos como sigue (roto).

Teno. Pago del lugar de Buenavista.

Tenoya. Pago del lugar de San Lorenzo, en Canaria.

Teror ó Terori. Lugar de Canaria. El camino desde Moya es áspero, por lo peligroso de las Vueltas del Rapador; pero se pasa en recompensa por la referida Montaña de Doramas. Divide las dos jurisdicciones un barranco. La población yace en un profundo y ameno valle, adornado de todo género de árboles frutales. Incomódanle mucho los barros en los inviernos, mas en el verano es país sumamente divertido. Hay mucho número de vecinos arruados en calles, plazuelas y casas muy decentes. Su nueva Iglesia, en donde se venera la Santa imagen de Nuestra Señora del Pino, es uno de los más bellos templos de las Canarias. La fuente de agua agria ó mineral, que consume la carne hasta el hueso, se suele recetar en algunos males.

Tierra de Trigo. Pago del lugar de los Silos.

Tijarafe. Lugar de la Palma. Lo primero que se encuentra en el camino es el renombre ${ }^{18}$ "Time», risco de volcán renegrido y tan peinado que parece una alta muralla. La vereda es angosta y en caracol, de muy mal piso; con todo se sube á caballo. Pasado este risco, se sale á un cielo alegre y risueña campaña, en medio de cuyo camino se tropiesa con un barranco muy profundo que se llama "Horadado" $"$. Sería imposible ir adelante, si la Naturaleza no hubiera venido al socorro. Ella formó como el arco de un puente en la piedra viva, que tendrá de grueso como de cuatro varas y por alli se pasa. El ayre es destemplado en frío y en calor. Abunda en trigo, de que la Isla es escasa.

\footnotetext{
${ }^{18}$ [Así en el original, pero debe ser renombrado, tal y como Viera refleja].

19 [La documentación del periodo muestra que la forma más común es Barranco del Jurado o del Jorado].
} 
Tijarafe. Pago del lugar de Tijarafe, en la Palma.

Tijoco. Pago de la Villa de Adeje.

Tinisara $^{20}$. Pago del lugar de Tijarafe, en la Palma.

Tirajana. Lugar en Canaria. Tiene muchas aguas y frutas; pero es destemplado en frío y en calor, por lo que está espuesto á tercianas.

Topa á Ciegas. Pago del lugar de Barlovento, en la Palma.

Toscón. Pago del lugar de Tejeda.

Toscón. Pago del lugar de San Lorenzo, en Canaria.

Trapiche, El. Pago del lugar de Firgas, en Canaria.

Trasmontaña. Pago del lugar de Firgas, en Canaria.

Tres Palmas, Las. Pago de la Villa de Guía.

Triana. Pago del lugar de los Llanos, en la Palma.

Valencia. Pago del lugar de Arico.

Valle, El. Pago del lugar de Chasna.

Valle de arriba. Pago del Valle de Santiago, en Tenerife.

Valle de Figueras. Pago del lugar de Taganána.

Valle de Igueste. Pertenece al anterior [Valle de San Andrés].

Valle de Lucía. Pago del lugar de Taganána.

Valle de San Andrés. Lugar de Tenerife dista de Santa Cruz más de dos leguas de agrio y peligroso camino. Es muy alegre, de buen temperamento, con buena playa y una torre. Llámase también Valle de Salazar. Hay viñas.

Valle de San Andrés. Pago de la Ciudad de la Laguna, en Tenerife.

Valle de Santiago. Lugar de Tenerife. Es villa de Señorío, perteneciente á la casa del Hoyo. Dista dos leguas de Buenavista y doce y media de la Laguna. Es terreno quemado y de temple frío. Al fin del Valle hay un puertecito de mar por donde es más frecuente el trato con la Gomera, pues en haciendo fuego, señal de pasagero, luego acude barco.

Valle de Tabares. Pago de la Ciudad de la Laguna.

Valle de Ximénez. Pago de la Ciudad de la Laguna.

Valle del Palmar. Pago del lugar de Buenavista.

Vera, La. Pago del lugar de San Juan de la Rambla.

${ }^{20}$ [En Viera viene la forma errada Tinixara]. 
Victoria. Lugar al este de Tenerife. Está en el término de Acentejoy sellama asi por la que consiguieron nuestros Españoles de los Guanches en otra acción. Es terreno de viñas y frutales. Dista de la Matanza media legua y tres de la Laguna. Las casas están dispersas.

Vilaflor. Véase Chasna.

Villa de la Orotava. En Tenerife. Yace á la falda del monte, de donde se levanta el "Teyde» casi á tres leguas de su cima, bajando de Sur a Norte y recostada sobre un terreno desigual. Domina sobre el Valle más rico, más ameno y más delicioso del Mundo. Se cree que no hay legua y media de tierra que produzca y valga tanto. Es de figura de erradura, toda plantada de vides, entretejida de los más bellos árboles frutales. Sus vistas á todas partes encantan. Al Sur, el monte verde, el bosque, las cumbres y el "Pico" con su alta cordillera nevada muchos meses; al Norte, el mar distante media legua, en cuyo puerto entran ó salen los buques mercantes, pescan las barcas y ofrece el Océano cada día espectáculos nuevos. A todos lados Viñas, levantadas del suelo en horquilla; huertas, jardines, árboles, casas de campo, quintas, montañas cortas, los lugares del Puerto de la Cruz, Realejos y aun en los días claros la isla de la Palma en perspectiva. Ni las casas del Pueblo se quitan la vista unas á otras, porque el terreno es muy pendiente y están casi en anfiteatro, lo que hace las calles molestas. Dista de la Laguna 5 leguas. El temple es muy benigno y muy sano. Jamás nieva, nevando copiosamente un cuarto de legua más arriba. Sería su cielo sin igual si los más de los días no se toldase de nubes con la Brisa que sopla del mar desde las nueve ó diez de la mañana; pero esto hace que el sol no arrebate el precioso fruto de las viñas. Los vientos meridionales suelen ser allí sumamente impetuosos con daño de los edificios y heredades. Atravieza toda la Villa una azequia de agua muy caudalosa, que baja desde la cumbre del Agua-mansa, riega las grandes huertas de la "Florida" y los "Sauces", mueve siete ó más molinos, abastece el pueblo, recogida después en dos grandes estanques, se reparte el riego de las viñas.

\section{Bibliografia}

[Álvarez Rixo, J.A.] (s.a.): Borrador manuscrito del Diccionario geográfico de estas Islas Canarias, intentado por el joven D. Cipriano Gorrín, natural del Puerto de la Cruz, en 1816. Archivo personal José Agustín Álvarez Rixo, JAAR 6/7, Biblioteca Universitaria de La Laguna.

- (1955): Cuadro histórico de estas Islas Canarias o Noticias Generales de sus estados y acontecimientos más memorables durante los cuatro años de 1808 a 1812. S. Benítez Padilla (prol.). Las Palmas de Gran Canaria, El Gabinete Literario. 
- (1982): Historia del Puerto del Arrecife. E. Romeu Palazuelos (prol.). Santa Cruz de Tenerife, Cabildo Insular de Tenerife.

- (1991): Lenguaje de los antiguos isleños. C. Díaz Alayón y A. Tejera Gaspar (eds.). La Laguna, Ayuntamiento del Puerto de la Cruz-Centro de la Cultura Popular Canaria.

- (1992): Voces, frases y proverbios provinciales de nuestras Islas Canarias con sus derivaciones, significados y aplicaciones. C. Díaz Alayón y F.J. Castillo (eds.). La Laguna, Instituto de Estudios Canarios.

- (1994): Anales del Puerto de la Cruz de La Orotava 1701-1872. M.T. Noreña Salto (introd.). Santa Cruz de Tenerife, Cabildo Insular de Tenerife-Ayuntamiento del Puerto de la Cruz.

Díaz Alayón, Carmen (1990): "Los estudios del español de Canarias en el siglo xix y la labor investigadora de José Agustín Álvarez Rixo". En Actas del Congreso de la Sociedad Española de Lingüística. xxAniversario. Madrid, Gredos, vol.i, págs. 382-392.

- (2003): "Lengua literaria y habla insular en José Agustín Álvarez Rixo». Revista de Filología de la Universidad de La Laguna, 21, págs. 105-133.

- (2004a): "Álvarez Rixo en la Sociedad de Amigos del País de La Palma». Revista de Asuntos Generales de la Isla de La Palma, 0, págs. 329-351.

- (2004b): «Notas y materiales sobre la producción periodística tardía de Álvarez Rixo". En Díaz Alayón, C. y Morera, M. (eds.): Homenaje a Francisco Navarro Artiles. Canarias, Academia Canaria de la Lengua-Cabildo Insular de Fuerteventura, págs. 155-200.

- (2005a): "Las páginas majoreras de la producción periodística de Álvarez Rixo". En Santana Henríquez, G. et al. (coords.): Con quien tanto quería . Estudios en Homenaje a María del Prado Escobar Bonilla. Las Palmas de Gran Canaria, Universidad, págs. 127-140.

- (2005b): "Sobre el comportamiento de los pronombres átonos en autores canarios de los siglos xviii y xix". Revista de Filología de la Universidad de La Laguna, 23, págs. 79-96.

- (2011): "Álvarez Rixo y sus observaciones al Diccionario de Historia Natural de las Islas Canarias". Revista de Filología de la Universidad de La Laguna, 29, págs. 37-72.

- (2014): «Sobre un texto inédito de Álvarez Rixo». Fortunatae, 25, págs. 99-114.

- (2016): "Las aportaciones lingüísticas de Álvarez Rixo». En Fernández Palomeque, P. (coord.): Escribir para no olvidar. La Laguna, Universidad, págs. 81-92.

Díaz Alayón, C. y Castillo, F.J. (2005): La obra periodística de José Agustín Álvarez Rixo. Estudio histórico y lingüístico. Canarias, Academia Canaria de la Lengua.

- (2006): «Sobre Álvarez Rixo, Lemos Smalley y la etnografia insular». Revista de Estudios Generales de la Isla de La Palma , 2, págs. 565-605.

- (2007): "Álvarez Rixo y Elizabeth Murray: rectificaciones y notas sobre un manuscrito". Revista de Filología de la Universidad de La Laguna, 25, págs. 97-105.

- (2008a): Los estudios históricos y lingüísticos de Dominik Josef Wölfel. Santa Cruz de Tenerife, Ediciones Idea. 
- (2008b): "Sobre la obra de José Agustín Álvarez Rixo: notas a dos textos de viaje». Cartas Diferentes. Revista Canaria de Patrimonio Documental, 4, págs. 105-174.

- (2009): "Notas a los Catálogos de los diversos manuscritos de mi pertenencia y personal trabajo". Tebeto, xix, págs. 305-351.

Millares Carlo, A. y Hernández Suárez, M. (1975): Biobibliografía de escritores canarios. Siglos xvi, xviiy xviii. Las Palmas de Gran Canaria, Museo Canario-Cabildo Insular de Gran Canaria.

Viera y Clavijo, J. de (1982): Noticias de la historia general de las Islas Canarias (2 vols.). A. Cioranescu (ed.). Santa Cruz de Tenerife, Goya ediciones. 